\title{
EDITORIAL
}

\section{The role of developmental theory in prevention and intervention}

\author{
DANTE CICCHETTI AND SHEREE L. TOTH \\ Mt. Hope Family Center, University of Rochester
}

Despite the logical links that exist between the provision of psychotherapeutic interventions to children and adolescents and developmental theory and research, too few bridges have been forged between these realms of knowledge (Cicchetti, Toth, \& Bush, 1988; Shirk, 1988). The reliance on adultderived guidelines for the classification of child psychopathology is but one example of the paucity of developmental theorizing in the field of psychiatric diagnosis. Because we have embraced frameworks rooted in adult psychopathology in order to classify childhood disorders, it is not surprising that we similarly have sought to apply principles derived from adult therapy to interventions with children and adolescents. Unfortunately, the "developmental continuity myth" of psychotherapy (Shirk, 1988) is likely to impede efforts to provide more theoretically guided, developmentally appropriate services to children and adolescents.

In fact, prevention efforts historically have been based in the areas of public health, epidemiology, and community psychology. Although the prevention programs emerging from these movements have been very important, little developmental influence has been present in the conceptualization, implementation, or evaluation of these initiatives. Similarly, although the psychoanalytic tradition and its

Our work on this special issue was supported by a grant from the Prevention Research Branch of NIMH (1 R01MH45027-01A1). application to child therapy certainly is rooted within developmental theory, empirically based developmental theory has been all but nonexistent in its incorporation into the design of approaches to child therapy.

Fortunately, the last decade has witnessed an increase in dialogue between basic researchers and those invested in providing developmentally guided prevention and intervention to children and adolescents. A major impetus in this regard has emanated from developmental psychopathology, an approach that advocates for a reciprocal interplay between normal developmental theory and findings derived from risk and psychopathological populations (Cicchetti, 1984, 1990a; Cicchetti \& Toth, 1991; Rutter, 1986). As the interface between normal and abnormal development has become increasingly strong, the application of findings conceptualized within this genre to prevention and intervention efforts has begun to blossom. The value of applying a developmental psychopathology perspective to prevention and intervention efforts is captured by Sroufe and Rutter (1984), who stated that by

. . . thoroughly understanding factors that pull subjects toward or away from increased risk at various age periods, one not only acquires a deeper understanding of development but one also gains valuable information for primary prevention. (p. 19)

Of course, before the potential inherent in a developmental psychopathology ap- 
proach to prevention and intervention could even begin to be realized, certain advances in our knowledge base of normal development and of risk conditions and psychopathology need to occur. We next highlight those achievements that we consider to be especially important.

As the power and influence of the behaviorist movement began to wane in this country, the 1960s ushered in an exciting period of several decades during which time the compelling theoretical ideas and experimental findings of Piagetian cognitive development dominated the field of developmental psychology (Cicchetti \& Pogge-Hesse, 1981; Hesse \& Cicchetti, 1982). Whereas Piaget's writings provided the impetus for and continue to stimulate many of the advances that have occurred in our understanding of cognitive growth, an unfortunate byproduct of this era was the relative neglect of other domains of development. So, for example, we possessed little information about the development of social and emotional processes and of the ways in which persons reasoned about social matters. Moreover, we knew virtually nothing about how various domains of the human mind interrelated, thereby precluding an in-depth understanding of the organization of normal and abnormal development (Cicchetti \& Schneider-Rosen, 1984; Cicchetti \& Sroufe, 1976; Emde, Gaensbauer, \& Harmon, 1976). Much stimulating progress has been made over the course of the ensuing years, and we now know a great deal about the nonintellective aspects of the mind, including ways in which various ontogenetic domains such as emotion and cognition interrelate. In turn, this knowledge can be more easily assimilated by those seeking to intervene in cases of child maladaptation.

In addition to the advances that have been made in these vital aspects of developmental processes, the field has achieved major headway in charting the continuities and discontinuities of adaptive and maladaptive early functioning (see, e.g., Block \& Block, 1980; Rutter, 1989; Sroufe, 1983). The results of these investigations have underscored the intricacy of the developmental process, highlighted the importance of prevention and early intervention, and made us aware of the potential for positive or negative reorganizations at subsequent developmental periods despite the level of prior adaptation.

In the field of child and adolescent psychopathology, parallel achievements have enabled developmental psychopathologists to contribute to prevention and treatment efforts. Our knowledge of the incidence and prevalence rates of various child and adolescent risk conditions and disorders has increased (Angold \& Costello, 1991; Costello, 1989; Institute of Medicine, 1989; Rutter, 1988). Likewise, our information on the etiology and longitudinal course of these highrisk conditions and psychopathological disorders has grown (Cicchetti \& Toth, 1992; Robins \& Rutter, 1990; Rolf, Masten, Cicchetti, Nuechterlein, \& Weintraub, 1990). As a consequence, etiological models of disorder increasingly reflect the true complexity inherent in the emergence and development of pathology (e.g., Sroufe, 1989). Moreover, the burgeoning number of longitudinal investigations of the course of various disorders has provided clues for the processes and mechanisms underlying continuity versus change in disordered functioning throughout the life course.

In moving beyond general issues in normal and abnormal development, a developmental psychopathology approach to service provision warrants consideration of a number of areas. To begin, the hierarchically organized nature of development possesses important implications for prevention and intervention. Because the successful resolution of each stage-salient issue is marked by the integration and organization of its structures, domains, and contents, each issue of development is integrated and coordinated with subsequently emerging issues. Moreover, all stage-salient issues are life-span issues and as such evidence continued differentiation and organization. At each point of reorganization, the resulting disequilibrium causes the individual to be especially amenable to change. Whether the period of reorganization re- 
sults in vulnerability or positive adaptation is determined largely by the individual's success in negotiating prior developmental tasks. For example, vulnerability to maladaptation is exacerbated in those who have experienced failure on a previous stagesalient issue. Similarly, individuals with a history of successful resolution of stagesalient issues are more likely to deal adaptively with periods of reorganization. However, regardless of the quality of prior adaptation, an individual's level of functioning can change at any time during the life course. Because periods of transition offer opportunities for change, it might be especially important to target prevention and intervention efforts at these periods of reorganization. The provision of "booster services" during developmental transitions, especially for those individuals with a history of serious difficulties, also holds great promise for facilitating positive outcome.

The realization that ontogenesis is an integrated and complicated process, characterized by multiply determined pathways and outcomes that interact in a complex system of biological, psychological, and environmental factors, also underscores the need for interventions to attend to the developmental dimension. Specifically, considerations such as when (i.e., the timing) and why a disorder occurs, how long it persists, and the identification of the precursors to disordered functioning, all require a developmental approach to ensure that prevention and intervention strategies are timed and guided. In essence, to integrate potential compensatory factors successfully in an intervention, an in-depth understanding of an individual's level of developmental organization is necessary. Similarly, a developmental perspective requires that attention be paid to proximal and distal factors and processes that contribute to disordered outcomes. Thus, developmental psychopathologists may advocate a focus on subclinical indicators, such as how stage-salient issues are resolved and the integration and organization of various domains, as they try to prevent and treat risk conditions and disorders. The utilization of this approach should yield more rich and helpful information than that provided by research that focuses solely on distal outcome factors such as presence versus absence of a psychiatric diagnosis. We wish to stress that all prevention and intervention efforts must be sensitive to the child's developmental level and the changing meaning that problems and disorder have for children at different developmental levels (Toth \& Cicchetti, in press).

Finally, the area of resiliency also holds great promise as an avenue for facilitating the development of programs of prevention and intervention, as well as for contributing to developmental theory (Masten, Best, \& Garmezy, 1990). By examining and understanding the processes and mechanisms that contribute to adaptation in situations that more typically result in maladaptation, theoreticians and clinicians will be better able to devise ways of promoting positive outcome in high-risk populations (Cicchetti, 1990b).

In a recent article appearing in the $A m e r-$ ican Journal of Community Psychology, Koretz (1991) emphasized the importance of conducting methodologically rigorous preventive interventions as tests of theory. An important avenue to pursue in this regard relates to the interface between unfolding developmental processes and intervention efforts. In particular, we believe that developmentally based preventive interventions may serve as a means for testing developmental theory and that, conversely, strategies of prevention and intervention can be based on normal ontogenetic principles. For example, because our knowledge of the link between the successful resolution of stage-salient issues and future adaptation is growing (Cicchetti, Toth, \& Bush, 1988), the development of programs to prevent the emergence of psychopathology can benefit from our knowledge of the progression through these issues in nondisordered children. Similarly, empirical findings from the evaluation of preventive interventions can serve to affirm, challenge, and enhance theories of normal development (Cicchetti, in press).

The contributors to this special issue in- 
corporate a developmental perspective into their approaches to prevention and intervention. The issue brings together a group of scholars who share a developmental viewpoint, though who often differ with respect to the theory that drives their work. We believe that this diversity is especially important for the growth of the field of developmental psychopathology as well as for progress in the prevention and treatment of childhood and adolescent disorders. In addition to the use of developmental theory, and despite differences in emphases, all contributors are committed to the integration of theory and research and to the application of this knowledge to problems of clinical import. The articles in this issue range from an emphasis on risk conditions

\section{References}

Angold, A., \& Costello, E. J. (1991). Developing a developmental epidemiology. In D. Cicchetti \& S. L. Toth (Eds.), Rochester Symposium on Developmental Psychopathology, Vol. 3: Models and integrations (pp. 75-96). Rochester, NY: University of Rochester Press.

Block, J. H., \& Block, J. (1980). The role of egocontrol and ego resiliency in the organization of behavior. In W. A. Collins (Ed.), Minnesota Symposia on Child Psychology (Vol. 13, pp. 39-101). Hillsdale, NJ: Erlbaum.

Cicchetti, D. (1984). The emergence of developmental psychopathology. Child Development, 55, 1-7.

Cicchetti, D. (1990a). An historical perspective on the discipline of developmental psychopathology. In J. Rolf, A. Masten, D. Cicchetti, K. Nuechterlein, \& $\mathrm{S}$. Weintraub (Eds.), Risk and protective factors in the development of psychopathology (pp. 2-28). New York: Cambridge University Press.

Cicchetti, D. (1990b). The organization and coherence of socioemotional, cognitive, and representational development: Illustrations through a develop. mental psychopathology perspective on Down syndrome and child maltreatment. In R. Thompson (Ed.), Nebraska Symposium on Motivation, Vol. 36. Socioemotional development (pp. 259-366). Lincoln: University of Nebraska Press.

Cicchetti, D. (in press). What developmental psychopathology is about: Reactions, reflections, projections. Developmental Review.

Cicchetti, D., \& Pogge-Hesse, P. (1981). The relation between emotion and cognition in infant development: Past, present, and future perspectives. In $\mathbf{M}$. Lamb \& L. Sherrod (Eds.), Infant social cognition: Empirical and theoretical considerations (pp. 205272). Hillsdale, NJ: Erlbaum.

Cicchetti, D., \& Schneider-Rosen, K. (1984). Theoretical and empirical considerations in the investigation of the relationship between affect and cognition in atypical populations of infants: Con- to the treatment of clinical disorders. Moreover, attention is directed to the promotion of competence on stage-salient issues as well as to the amelioration of risk and psychopathology. These foci are commensurate with goals articulated by innovators in the area of prevention (e.g., Koretz, 1991; Rolf, 1985).

In the future, it is likely that we will learn the most about the causes, course, and sequelae of disorders across the life span by charting normal developmental trajectories and incorporating this knowledge into the development of our approaches to prevention and intervention. We think you will agree that the articles in this special issue reflect an important step in this direction.

tributions to the formulation of an integrative theory of development. In C. Izard, J. Kagan, \& R. Zajonc (Eds.), Emotions, cognition and behavior (pp. 366-406). New York: Cambridge University Press.

Cicchetti, D., \& Sroufe, L. A. (1976). The relationship between affective and cognitive development in Down's syndrome infants. Child Development, 47 , 920-929.

Cicchetti, D., \& Toth, S. L. (1991). The making of a developmental psychopathologist. In J. Cantor, C. Spiker, \& L. Lipsitt (Eds.), Child behavior and development: Training for diversity (pp. 34-72). Norwood, NJ: Ablex.

Cicchetti, D., \& Toth, S. L. (Eds.). (1992). Rochester Symposium on Developmental Psychopathology, Vol. 4: Development perspectives on depression. Rochester, NY: University of Rochester Press.

Cicchetti, D., Toth, S. L., \& Bush, M. (1988). Developmental psychopathology and incompetence in childhood: Suggestions for intervention. In B. Lahey \& A. Kazdin (Eds.), Advances in clinical child psychology (Vol. 11, pp. 1-71). New York: Plenum.

Costello, E. J. (1989). Developments in child psychiatric epidemiology. Journal of the American Academy of Child and Adolescent Psychiatry, 28, 836841.

Emde, R., Gaensbauer, T., \& Harmon, R. (1976). Emotional expression in infancy: A biobehavioral study. Psychological Issues Monograph Series, 10(Serial No. 37).

Hesse, P., \& Cicchetti, D. (1982). Toward an integrative theory of emotional development. New Directions for Child Development, 16, 3-48.

Institute of Medicine. (1989). Research on children and adolescents with mental, behavioral, and developmental disorders. Washington, DC: National Academy Press.

Koretz, D. (1991). Prevention-centered science in men- 
tal health. American Journal of Community Psychology, 19, 453-458.

Masten, A., Best, K., \& Garmezy, N. (1990). Resilience and development: Contributions from the study of children who overcome adversity. Development and Psychopathology, 2, 425-444.

Robins, L., \& Rutter, M. (Eds.). (1990). Straight and devious pathways from childhood to adulthood. Cambridge: Cambridge University Press.

Rolf, J. (1985). Evolving adaptive theories and methods for preventive research with children. Journal of Consulting and Clinical Psychology, 53, 631646.

Rolf, J., Masten, A., Cicchetti, D., Nuechterlein, K., \& Weintraub, S. (Eds.). (1990). Risk and protective factors in the development of psychopathology. New York: Cambridge University Press.

Rutter, M. (1986). Child psychiatry: The interface between clinical and developmental research. Psychological Medicine, 16, 151-169.

Rutter, M. (1988). Epidemiological approaches to developmental psychopathology. Archives of General Psychiatry, 45, 486-495.

Rutter, M. (1989). Intergenerational continuities and discontinuities in serious parenting difficulties. In
D. Cicchetti \& V. Carlson (Eds.), Child maltreatment: Theory and research on the causes and consequences of child abuse and neglect (pp. 317-348). New York: Cambridge University Press.

Shirk, S. (Ed.). (1988). Cognitive development and child psychotherapy. New York: Plenum.

Sroufe, L. A. (1983). Infant-caregiver attachment and patterns of adaptation in preschool: The roots of maladaptation and competence. In M. Perlmutter (Ed.), Minnesota Symposium in Child Psychology (pp. 41-83). Hillsdale, NJ: Erlbaum.

Sroufe, L. A. (1989). Pathways to adaptation and maladaptation: Psychopathology as developmental deviation. In D. Cicchetti (Ed.), Rochester Symposium on Developmental Psychopathology, Vol. 1: The emergence of a discipline (pp. 13-40). Hillsdale, NJ: Erlbaum.

Sroufe, L. A., \& Rutter, M. (1984). The domain of developmental psychopathology. Child Development, 55, 17-29.

Toth, S. L., \& Cicchetti, D. (in press). Child maltreatment: Where do we go from here in our treatment of victims? In D. Cicchetti \& S. L. Toth (Eds.), Child abuse, child development, and social policy. Norwood, NJ: Ablex. 